\title{
REVITALISASI KESENIAN LAMUT DI KALIMANTAN SELATAN
}

\section{LAMUT ART REVITALIZATION IN SOUTH KALIMANTAN}

\author{
Agus Yulianto \\ Balai Bahasa Provinsi Kalimantan Selatan, Jalan A. Yani, Km 32,2 Loktabat, Banjarbaru, Kalimantan Selatan; \\ email:agusb.indo@gmail.com
}

Diterima 8 Februari 2015

Direvisi 15 September 2015

Disetujui 4 Oktober 2015

\begin{abstract}
Abstrak. Lamut adalah seni tutur khas masyarakat Banjar, Kalimantan Selatan. Kesenian lamut merupakan teater tutur tunggal dan hanya diiringi oleh satu alat musik yang bernama tarbang lamut. Lamut sudah mulai ditinggalkan generasi muda akibat dari kemajuan teknologi dan gaya hidup. Tujuan penelitian ini adalah untuk mengetahui apakah lamut dapat direvitalisasi. Metode yang dipakai dalam penelitian ini adalah metode deskriptif dengan teknik studi pustaka dan observasi. Hasil dari penelitian dapat diketahui antara lain pagelaran lamut terbagi menjadi dua, yaitu untuk pertunjukkan dan upacara. Isi cerita lamut sudah baku dan banyak mengandung nilai-nilai kebaikan. Melalui bengkel sastra, revitalisasi kesenian lamut berhasil dilakukan.
\end{abstract}

Kata kunci: seni tutur, revitalisasi, lamut, masyarakat Banjar, Kalimantan Selatan

\begin{abstract}
Lamut is a speciefic oral art of Banjarese, South Borneo. Lamut is a single oral theatre and accompanied by a musical instrument, namely tarbang Lamut. This oral art is becoming obsolete for youth as a result of technological advance and change of lifestyle. The method used is descriptive and library research technique The result tells that lamut performance consists of two types, for entertainment and ceremony. The content of Lamut story is standard and it containns moral values. The Lamut revitalization effort through literary workshop (bengkel sastra) has been done successfully.
\end{abstract}

Keyword: oral art, revitalisation, lamut, Banjarese society, South Kalimantan

\section{PENDAHULUAN}

Provinsi Kalimantan Selatan memiliki kekayaan sastra daerah yang beraneka ragam. Salah satunya adalah sastra daerah Banjar. Sastra daerah Banjar adalah sastra yang tumbuh dan berkembang di tengah-tengah masyarakat Banjar dan diwariskan turun temurun dari mulut ke mulut. Dikatakan sastra daerah Banjar sebab di Provinsi Kalimantan Selatan yang didiami oleh beberapa suku bangsa, suku Banjar merupakan suku mayoritas yang menempati hampir di semua wilayah tersebut.

Suku Banjar memiliki sastra lisan yang cukup beraneka ragam. Sastra lisan Banjar adalah sastra yang lahir, tumbuh, dan berkembang di Kalimantan Selatan. Sastra lisan Banjar tumbuh dan berkembang seiring dengan pertumbuhan dan perkembangan masyarakatnya. Sastra lisan Banjar ini merupakan hasil proses budaya yang panjang dan di dalamnya berisi persoalan yang beragam tentang kehidupan manusia itu sendiri (Effendi 1997: 1).

Sastra lisan Banjar dapat berbentuk pertunjukkan dan bukan pertunjukkan. Sastra lisan Banjar yang berupa pertunjukkan memang ditampilkan untuk ditonton oleh banyak orang dan berfungsi sebagai media hiburan dan pendidikan. Hal itu sesuai dengan manfaat sastra lisan itu sendiri yang paling tidak dapat dikaitkan dengan fungsi pemberi keindahan dan kegunaan (dulce et utile) (Wellek dan Warren 1995: 25). Fungsi keindahan sastra lisan tercermin dalam kemerduan permainan bunyi, keteraturan irama, gaya bahasa dan majas, penyajian yang memikat, menyejukkan perasaan, dan menimbulkan rasa keindahan sehingga kenyataan hidup yang kurang menyenangkan terlupakan untuk sesaat. Kegunaan sastra lisan terwujud dalam isinya yang bersifat didaktis-konstruktif, yaitu mengandung pengajaran dan bimbingan moral. Dalam sastra lisan dapat ditemukan 
pengajaran dan keteladanan, terutama tentang kearifan hidup, hidup bermasyarakat, dan kehidupan beragama (Sudjiman 1995: 15).

Sastra lisan Banjar yang berbentuk pertunjukan berupa madihin, lamut, bapandung, dan mamanda. Sastra daerah Banjar yang berupa pertunjukkan ini telah sekian lama menjadi sarana hiburan dan juga penanaman moral dan tingkah laku bagi masyarakat Banjar itu sendiri. Kekayaan budaya Banjar yang tertuang dalam seni pertunjukan ini seharusnya dapat menjadi sarana bagi promosi wisata yang ada di daerah Kalimantan Selatan. Kalimantan Selatan telah lama terkenal dengan pasar terapung dan juga bekantannya. Akan tetapi, seni pertunjukkan sastra lisan Banjar terkesan kalah oleh seni pertunjukkan kontemporer seperti pertunjukkan musik dan drama sinetron di televisi. Padahal dengan mengetahui seni pertunjukkan sastra daerah Banjar, masyarakat luar akan mengetahui tentang masyarakat Banjar. Hal itu disebabkan dalam seni pertunjukkan sastra daerah Banjar terkandung filosofi, pandangan hidup, dan karakteristik dari masyarakat Banjar itu sendiri.

Pengaruh kebudayaan pop sebagai bagian dari arus modernitas memang sedikit banyak mempengaruhi seni tradisi lisan di banyak daerah di Indonesia, tidak terkecuali di Kalimantan Selatan. Pergeseran animo masyarakat dari seni pertunjukkan asli daerah ke kebudayaan pop menjadi ancaman tersendiri bagi keberlangsungan kehidupan seni tradisi itu sendiri. Padahal, seni tradisi berupa sastra lisan Banjar merupakan karya agung dari nenek moyang dan menjadi bagian dari kebudayaan Indonesia itu sendiri.

Seni pertunjukkan sastra daerah Banjar terkesan kurang promosi dan kurang dikenal oleh masyarakat lain di luar wilayah Kalimantan Selatan. Masyarakat di luar wilayah Kalimantan Selatan lebih mengenal seni tradisi dari warga Dayak. Masyarakat di luar wilayah Kalimantan Selatan lebih mengidentikkan bahwa kesenian yang ada di pulau Kalimantan itu semata-mata adalah kesenian dari warga Dayak. Hal ini sungguh ironis mengingat begitu banyak dan beragamnya kesenian yang terdapat pada masyarakat Banjar di Kalimantan Selatan. Keberagaman seni tradisi lisan masyarakat Banjar itu tertuang dalam seni tradisi lisan berupa puisi seperti pantun, syair, mantra, petatah-petitih, ungkapan, peribahasa, dan juga madihin. Juga tertuang dalam bentuk prosa seperti cerita rakyat yang berupa dongeng, legenda, dan mite serta tertuang dalam bentuk drama seperti mamanda dan bapandung. Seni pertunjukkan sastra daerah Banjar yang terkesan jalan di tempat atau kalau boleh dikatakan mundur mengkhawatirkan banyak pihak.

Sastra daerah Banjar yang di dalamnya tercakup tradisi/sastra lisan dalam arus modernisasi seperti saat ini memang cenderung termarjinalkan. Padahal, sastra tradisi sesungguhnya merupakan warisan leluhur yang senantiasa harus dijaga dan dilestarikan.

Demikian pula yang terjadi pada tradisi lisan Banjar berupa kesenian lamut. Kesenian lamut selama berabad-abad telah ikut membantu pembentukan pola sikap, pola pikir, dan tingkah laku masyarakat pendukungnya. Hal itu disebabkan dalam lamut banyak memuat nilainilai, baik itu nilai pendidikan, moral, maupun budaya. Kesenian lamut ini menurut Asmuni (2012: 25) sebenarnya bukanlah kesenian asli masyarakat Banjar. Lamut adalah kesenian tutur asli masyarakat Tionghoa. Kesenian lamut ini dibawa para pedagang Tionghoa ke Banjar terus berkembang ke pahuluan hingga Amuntai pada tahun 1816.

Saat ini kesenian lamut berada dalam keadaan yang memprihatinkan. Kesenian ini terancam mengalami kepunahan. Kepunahan itu diakibatkan antara lain tidak adanya regenerasi dari seniman lamut itu sendiri dan di sisi yang lain para seniman lamut di Kalimantan Selatan rata-rata sudah berusia tua.

Keberadaan kesenian lamut di Kalimantan Selatan saat ini sangat memprihatinkan. Banyak generasi muda Banjar yang sudah tidak mengenal lagi kesenian lamut ini. Arus modernisasi dan kemajuan teknologi membawa dampak yang kurang baik bagi kesenian lamut ini. Masyarakat mulai memilih menikmati hiburan dari televisi, internet, VCD, dan juga radio dibandingkan harus menonton pertunjukkan lamut. Hal itu mengakibatkan jarang sekali kesenian lamut ditampilkan di depan publik atau masyarakat. 
Oleh sebab itu tidak heran bila masyarakat sedikit demi sedikit mulai melupakan keberadaan kesenian lamut ini. Selain akibat arus modernisasi dan kemajuan teknologi, harus diakui kemunduran kesenian lamut ini juga diakibatkan masa pentas kesenian lamut yang terlalu lama (satu kali pertunjukkan dapat memerlukan waktu 8 jam) sehingga cenderung membosankan. Demikian juga dengan lamut tatamba (lamut untuk pengobatan) mengalami kemunduran yang cukup memprihatinkan. Hal itu disebabkan dalam lamut tatamba terdapat ritual yang dianggap bersentuhan dengan alam gaib yang sedikit banyak bertentangan dengan akidah Islam.

Seniman lamut rata-rata sudah berusia tua dan mengalami kesulitan untuk melakukan regenerasi terhadap generasi muda yang mau untuk menguasai kesenian lamut itu sendiri. Hal ini bila dibiarkan terus tidak menutup kemungkinan bila kesenian lamut ini suatu saat hanya tinggal nama saja. Oleh sebab itu membicarakan tentang revitalisasi sastra lisan lamut ini menjadi menarik untuk dilakukan.

Penelitian atau tulisan tentang lamut ini telah banyak dilakukan, antara lain:

1. Mugeni, dkk. tahun 2004 yang berjudul Sketsa Sastra Kalimantan Selatan: Lamut.

2. Pahmi tahun 1998 yang berjudul Sejarah Kesenian Lamut di Kalimantan Selatan.

3. Bahtiar Sanderta tahun 1988 yang berjudul Kesenian Lamut.

4. Syamsiar Seman tahun 1981 yang berjudul Kesenian Lamut dan Madihin sebagai Media Tradisional yang Komunikatif.

5. Syamsiar Seman tahun 1988 yang berjudul Kesenian Rakyat Kalimantan Selatan "Lamut".

6. Syamsiar Seman tahun 2010 yang berjudul Kesenian Tradisional Banjar: Lamut, Madihin, dan pantun.

\section{METODE}

Penelitian ini menggunakan metode deskriptif. Metode adalah suatu prosedur untuk mencapai suatu tujuan yang telah ditetapkan (Semi 1990: 105), sedangkan metode deskriptif adalah suatu metode untuk memperoleh informasi tentang kondisi yang ada pada suatu penelitian dilakukan dengan melukiskan kondisi "apa yang ada" itu.

Teknik adalah cara khas yang digunakan atau dilalui dalam mencapai tujuan yang telah ditetapkan dan dengan berpegang pada proses sistimatis yang terdapat dalam metode (Semi 1990: 105).

Dalam penelitian ini digunakan teknik studi pustaka, yaitu dengan mencari informasi dari buku-buku yang dianggap relevan dengan penelitian yang dilakukan. Buku tersebut dapat diperoleh dari perpustakaan atau koleksi pribadi. Selain itu, dilakukan juga teknik observasi, yaitu pengamatan langsung terhadap kegiatan bengkel sastra yang merevitalisasi kesenian lamut kepada generasi muda, khususnya siswa-siswa SLTA seKalimantan Selatan.

Sumber data penelitian ini adalah hal-hal yang berkaitan dengan lamut yang ada di Kalimantan Selatan.

\section{HASIL DAN PEMBAHASAN}

\section{Sekilas tentang Kesenian Lamut}

Sebelum membahas lebih jauh mengenai revitalisasi kesenian lamut ini ada baiknya untuk mengetahui terlebih dahulu mengenai kesenian lamut itu sendiri untuk mendapatkan gambaran yang jelas tentang kesenian tersebut. Ada sementara orang berpendapat bahwa teater lamut (balamut) asal-usulnya dari kesenian dundam, yaitu kesenian bercerita dengan alat yang sama dengan lamut yaitu terbang, pendundam duduk di sentral rumah, dengan perapian dupa dan menyan, apabila lampu dimatikan, maka mulailah pendundam bercerita. Tentu saja pendengarnya cuma melihat pendundam sama-samar dalam gelap. Cerita yang dibawakan pendundam adalah dongeng-dongeng kerajaan antah berantah. (Sanderta 1988: 2).

Pendapat tersebut bisa saja dibenarkan, karena perbedaan balamut dan badundam hanya pada aspek cerita saja, sedangkan aspek-aspek yang lainnya sama. Sementara itu, ada juga yang 
menyatakan nama kesenian lamut diambil dari nama salah satu tokoh cerita yaitu lamut (Mugeni dkk 2004: 43).

Pelamutan (orang yang membawakan lamut sama dengan dalang dalam cerita wayang) biasanya hanya menurunkan keahliannya membawakan lamut kepada keturunannya saja. Hal ini terjadi karena seniman lamut biasanya akan menikmati kehidupan yang layak sehingga pelamutan hanya lestari pada garis keturunan. Masa sekarang ini pelamutan tidak lagi dipergelarkan sebagai tontonan, tetapi lestari dalam upacara adat keturunan, upacara ini biasa disebut bahajat. Pada zaman kejayaannya, lamut sangat dihargai oleh masyarakatnya. Biasanya lamut dipergelarkan di lapangan atau pasar pada malam hari. Waktu yang dianggap tepat adalah pasar malam, sehingga penonton dari desa-desa berdatangan.
Lamut biasanya juga dipergelarkan untuk memeriahkan perkawinan dan setelah panen. Penonton tahan berjam-jam duduk di tanah berlapiskan tikar, kayu bahkan sendal hanya untuk menonton pelamutan membawakan cerita-cerita fantastis yang banyak mengandung perumpamaan dan ibarat yang dapat dijadikan sebagai pelajaran hidup dengan narasi dan dialog yang memikat, yang diiringi lagu-lagu yang menghibur. Pelamutan dengan caranya bercerita mempunyai keterampilan yang tidak dimiliki orang lain, baik dalam menyusun kata-kata bersyair maupun pola narasi dan dialog yang dramatik, irama terbang yang khas, mengiringi cerita pelamutan mengalun dengan asyik, selaras dengan suasana gembira, sedih, marah, perkelahian dan lain sebagainya (gambar 1). Ada satu segi yang selalu muncul dari pelamutan, yaitu humor spontan baik yang larut dalam cerita

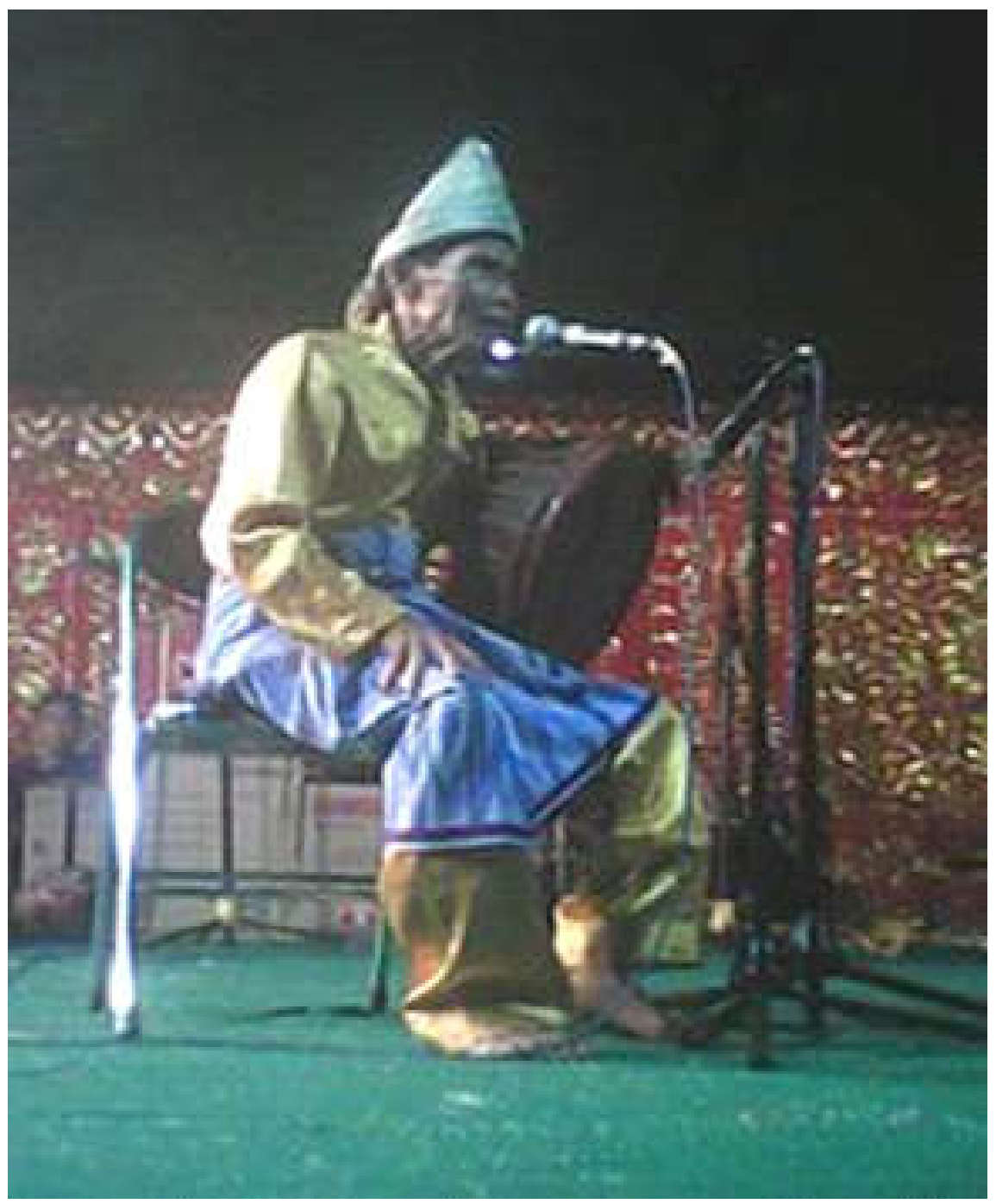

Gambar 1. Kesenian lamut 
maupun saat menanggapi celetukan para penonton. Demikian juga, walaupun cerita dan plot lamut telah dikenal, tetapi teknik permainan penokohan bisa dibumbui oleh syair dan pantun yang baru. Lamut sebagai seni pertunjukkan tidak menyediakan sesajen seperti lamut untuk upacara yang memerlukan sesajen berupa seperangkat piduduk (lambang pembayaran hajat) kecuali perapian dupa kemenyan dan kelapa muda untuk sang pelamutan (gambar 2).

Lamut dapat dipergelarkan dalam berbagai peristiwa seperti hajatan, nazar, maupun sebagai hiburan. Sebelum lamut dipergelarkan baik dalam kegiatan hajatan, nazar, atau hiburan biasanya selalu didahului oleh sebuah upacara kecil yang sudah mentradisi dalam setiap pergelaran lamut.

Berikut upacara kecil tersebut (Jarkasi dan Kawi 1996: 6)

1. Membakar pedupaan.

2. Menyediakan piduduk berupa: a) beras ketan, b) kelapa, c) gula merah, d) kopi manis/pahit, e) kue tradisiona, f) rokok daun, g) air putih, dan lain-lain.

3. Menyiapkan air kelapa muda untuk diminum palamutan.

4. Membaca doa selamat.
Fungsi dari upacara kecil ini menurut palamutan (orang yang membawakan cerita lamut) adalah sajian untuk para leluhur supaya pergelaran lamut tersebut dapat berjalan lancar.

Kesenian lamut ini biasanya diselenggarakan pada malam hari setelah sholat Isya atau pukul 20.00 WITA. Lamanya pertunjukkan bisa satu malam atau disesuaikan dengan keinginan penyelenggara.

Tempat penyelenggaraan lamut ini bisa di dalam ruangan luas, pekarangan, gedung atau di sawah yang telah kering. Patut untuk diketahui tempat palamutan duduk untuk membawakan cerita lamut adalah sebuah tempat khusus yang disebut cacampaan, yaitu sebuah pentas kecil berbentuk persegi panjang berukuran lebih 2 meter x 2,5 meter. Cacampaan ini biasanya diletakkan menghadap penonton dan dibuat agak tinggi sehingga palamutan dapat melihat penonton sampai di belakang. Untuk menimbulkan kesan artistik, cacampaan ini dapat dihiasi dengan berbagai dekorasi dan ditutup sisinya dengan kain sasirangan (kain khas masyarakat Banjar). Mengingat lamanya pertunjukkan lamut ini, tempat duduk palamutan biasanya diberi bantal atau sesuatu yang agak kenyal agar palamutan

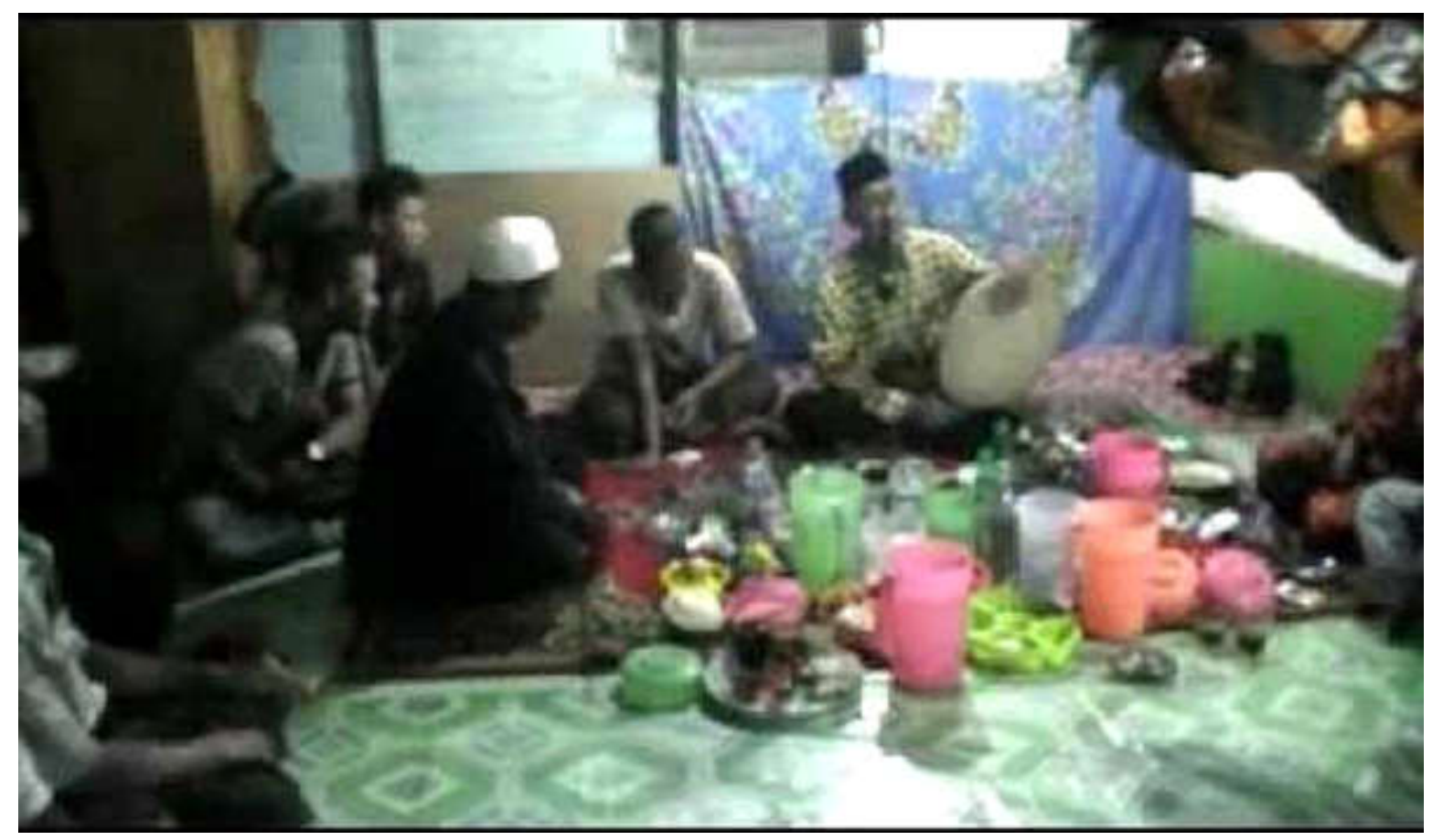

Gambar 2. Pidudukuntuk lamut tatamba(pengobatan) 
merasa nyaman dalam membawakan pertunjukkannya (gambar 3).

Selain di tempat-tempat yang telah disebutkan di atas, pergelaran lamut kadang-kadang dibuat tempat khusus berbentuk balai-balai ukuran kecil dan diberi atap untuk langit-langitnya. Dahulu, sebelum ada listrik untuk menunjang pergelaran lamut ini digunakan lampu petromaks. Palamutan duduk di atas cacampaan dan para penonton duduk lesehan di sekitar palamutan berpakaian sehari-hari atau menggunakan sarung. Para penonton biasanya membawa kue-kue kecil tradisional seperti singkong, kacang rebus, gula merah, dan sebagainya yang mereka santap sambil menonton pertunjukkan lamut.

Saat ini pertunjukkan lamut relatif tidak berubah. Terutama lamut yang dipentaskan untuk pengobatan (tatamba). Pementasan lamut untuk hiburan sedikit demi sedikit mengalami perubahan, terutama dari segi lamanya waktu pementasan yang sudah mulai berkurang dibandingkan pementasan lamut pada zaman dahulu yang memerlukan waktu semalam suntuk. Saat ini lamut untuk hiburan dapat dipentaskan beberapa jam saja sesuai dengan keperluan orang yang mempunyai hajat.

Pertunjukkan atau pergelaran lamut selalu dibantu oleh sebuah alat musik tradisional yang bernama tarbang lamut. Tarbang lamut ini lebih besar dibandingkan tarbang rabana. Biasanya tarbang lamut dibuat dalam ukuran rata-rata lebih kurang $25 \mathrm{~cm}$ dan diameter $50-60 \mathrm{~cm}$, dari bahan kayu pilihan seperti jingah (melaronea), madang (gordonia) dan lain-lain yang dikombinasikan oleh kulit kambing serta disimpai (diikat) dengan rotan (Jarkasi dan Kawi1996: 7).

Ketika palamutan membawakan cerita lamut, tarbang ini diletakkan di atas paha atau dirangkul dengan posisi kaki bersila. Palamutan sudah memukul tarbang sebelum cerita dimulai (seperti intro dalam musik). Selanjutnya irama pukulan tarbang disesuaikan dengan jalan cerita. Pukulan tarbang dalam lamut ini lebih berfungsi sebagai penghidup jalan cerita. Bila cerita bernuansa duka maka pukulan tarbang lamut disesuaikan dengan suasana duka. Demikian juga dengan suasana- suasana lainnya seperti gembira, indah, sedih, dan sebagainya.

Di samping tarbang lamut ada satu alat lagi yang biasanya selalu mengiringi pertunjukkan lamut yaitu pedupaan. Pedupaan ini mengepul dari awal sampai akhir cerita. Penggunaan pedupaan ini menimbulkan efek mistis dan khusyuk dalam pertunjukkan. Penggunaan pedupaan ini lebih bersifat mistik, yaitu adanya suasana khusus dan komunikatif dengan makhluk/roh halus yang mungkin hadir dalam acara atau pertunjukkan lamut tersebut. Jika pertunjukkan lamut tersebut diperuntukkan untuk memenuhi nazar (janji pada diri sendiri jika maksud tercapai)/hajat maka tuan rumah biasanya juga menyediakan aneka ragam makanan dan kue. Sering pula disediakan piduduk, kopi pahit, air kelapa, air putih, dan rokok daun. Isi piduduk biasanya berupa beras ketan, kelapa, telur ayam, gula merah, benang hitam, jarum, dan uang logam sekedarnya (Jarkasi dan Kawi 1996: 6).

Lamut adalah sebuah seni pertunjukkan tunggal yang dimainkan secara bertutur oleh palamutan. Oleh sebab itu, lamut disebut juga teater tutur. Jadi, palamutan yang membuat karakter tokoh yang ada dalam cerita. Dengan demikin, penokohan yang ada dalam lakon/cerita bersifat abstrak. Seni pertunjukkan lamut ini hampir sama dengan seni pedalangan di masyarakat Jawa. Bedanya, bila dalam pedalangan ada benda berupa wayang yang dijadikan simbol cerita (tokoh atau latar) sedangkan dalam lamut semua unsur cerita bersifat imajinatif. Oleh karena itu, sebagai palamutan ia adalah sutradara di dalam menciptakan karakter yang dinamis walaupun karakter tokoh cerita itu sudah baku (Seman 1988: 15)

Adapun struktur lakon dalam pertunjukkan lamut adalah:

1. Dibuka dengan tatabuan tarbang dan nyanyian pembukaan terdiri atas pantun dan syair-syair. Semua itu dilakukan oleh palamutan sendiri.

2. Babak demi babak lakon diselingi dengan pantun dan lelucon.

3. Ditutup dengan tatabuhan serta nyanyian. 


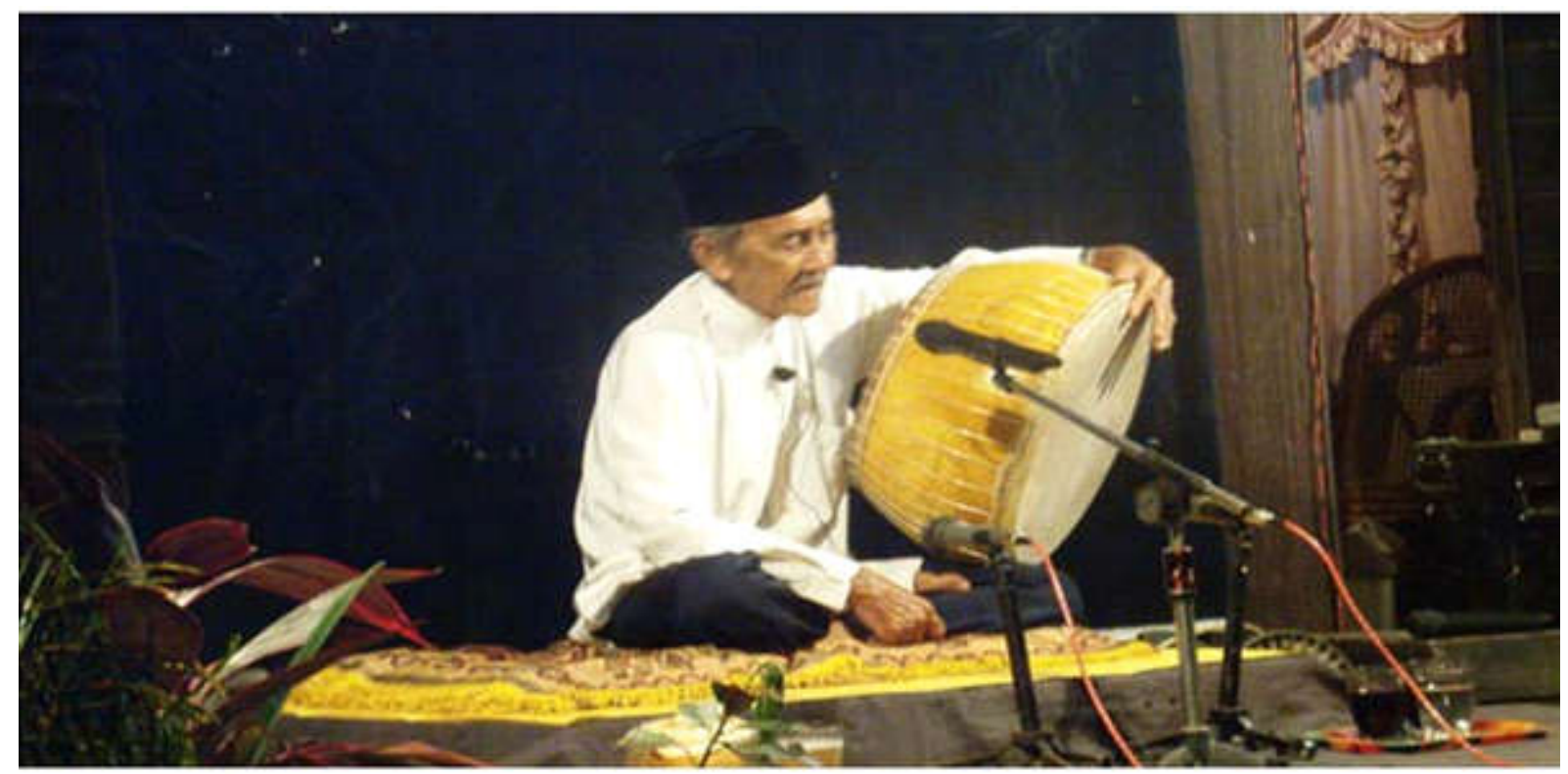

Gambar 3. Kesenian lamut

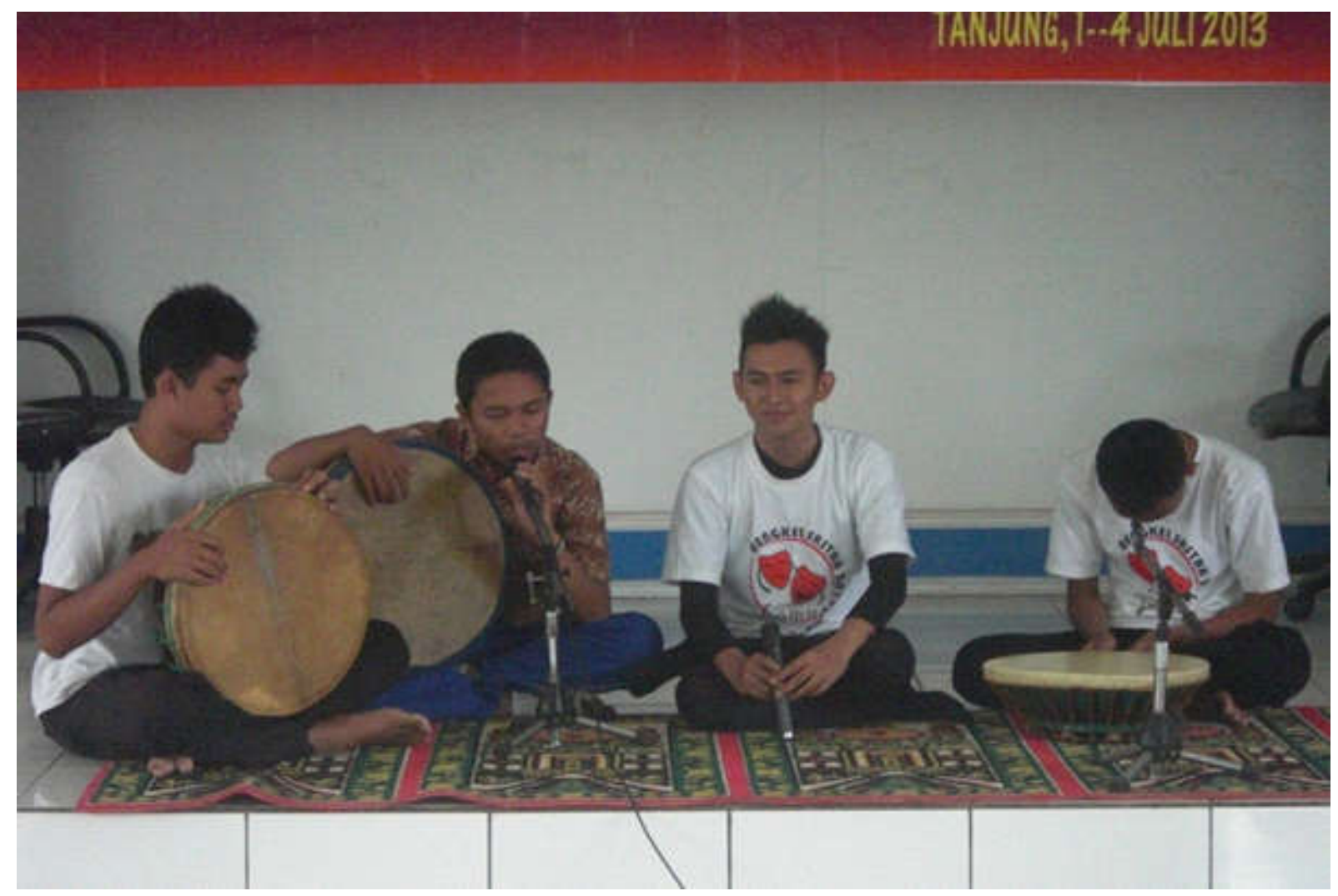

Gambar 4. Siswa peserta bengkel sastra sedang pentas kesenian lamut 


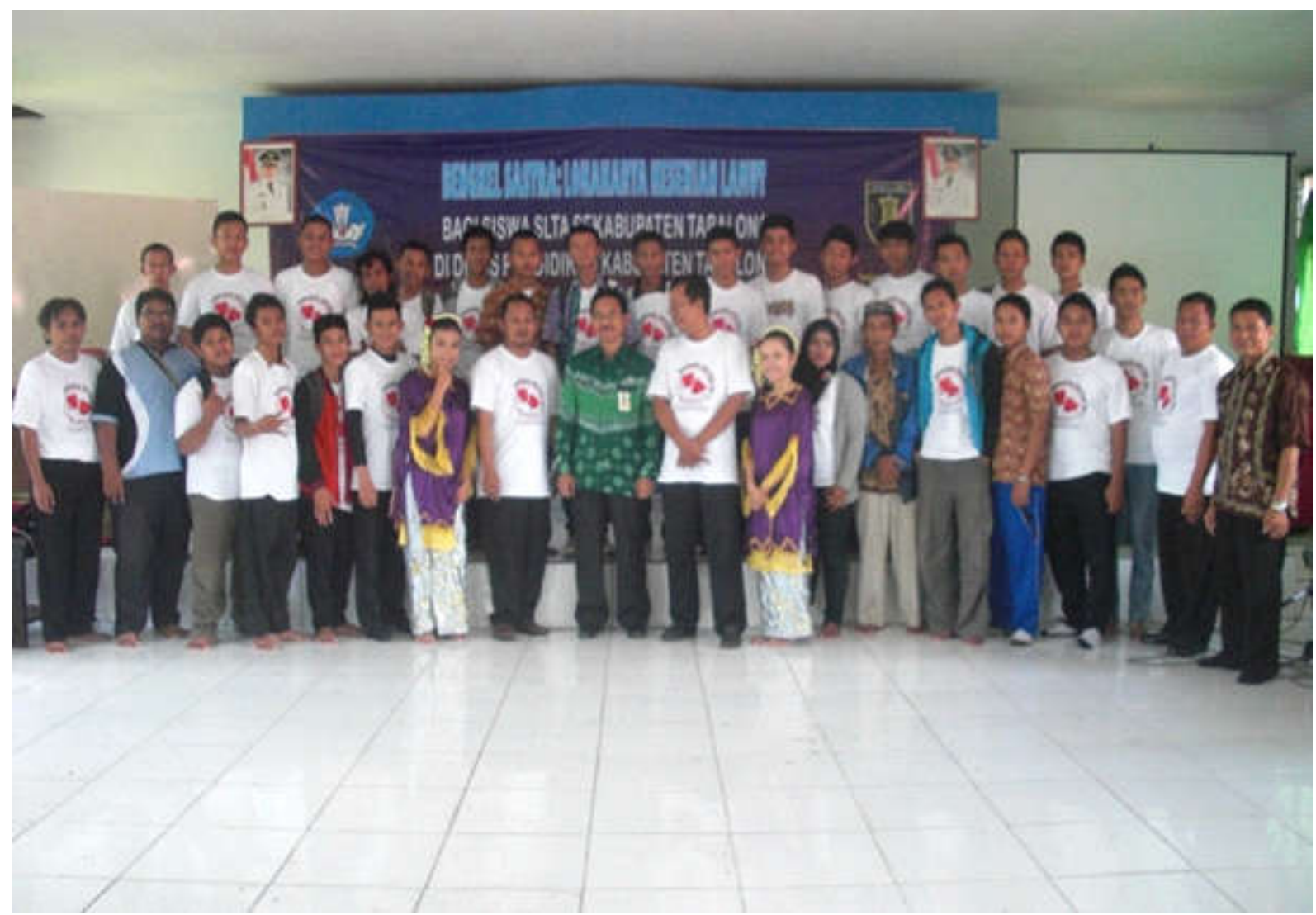

Gambar 5. Kegiatan bengkel sastra lamut

Struktur umum ini mengandung struktur khusus di dalam babak yakni sebagai berikut:

1. Bercerita sebagai narator.

2. Berdialog yang dilaksanakan secara terampil oleh palamutan sendiri.

3. Bercerita kembali (Seman 1988: 15).

Lamut dalam masyarakat Banjar mempunyai dua fungsi, yaitu: (1) lamut sebagai seni untuk upacara dan (2) lamut sebagai seni hiburan.

Lamut sebagai seni upacara adalah semacam upacara "tolak bala" atau doa selamat, yakni sesudah kelahiran anak atau sesudah sunatan, membayar hutang (janji). Upacara tersebut dimulai dengan mamundang (mengundang) tokoh-tokoh alam gaib yang dilakukan oleh palamutan dengan mengucapkan mantera-mantera (Sanderta 1988: 2). Sebelum lamut dipertunjukkan biasanya dilengkapi oleh sesajen berupa: bubur merah, bubur putih, beras, ketan, telur, kelapa muda, ayam panggang, dsb. Lamut sebagai seni hiburan dan tontonan tidak menyediakan sesajen kecuali perapian dupa kemenyan dan kelapa muda (Seman 1981: 2). Saat ini fungsi lamut hanya sebagai pembayar nazar dan pengobatan (Jarkasi dan Kawi 1996: 27). Hal itu disebabkan oleh derasnya arus kemajuan zaman seperti adanya TV, Radio, VCD yang mengemas hiburan dalam bentuk seni modern sehingga sedikit demi sedikit menggeser kedudukan seni lamut sebagai seni hiburan.

Lamut sebagai salah satu bentuk kesenian Banjar memiliki kisah tersendiri. Dilihat dari segi kisahan, seni lamut sama dengan cerita wayang dan apabila dilihat dari segi pengembangan cerita lamut dapat dikreativitaskan oleh palamutan sesuai dengan keperluan. Cerita lamut di samping memberikan daya hiburan kepada penonton juga dapat berfungsi sebagai pemenuhan suatu hajat atau nazar si penyelenggara. Oleh sebab itu, cerita lamut disusun sedemikian rupa mengarah kepada adanya kelompok jahat dan baik, sedangkan dari segi tema berkisar pada masalah-masalah kedigjayaan serta hal-hal yang berhubungan 
dengan mitos. Tokoh yang memiliki kekuatan supranatural yang akan dipuji dan disanjung masyarakat. Kekuatan supranatural ini biasanya menyangkut alam nyata dan alam gaib.

Berikut ini contoh ringkasan cerita lamut yang sudah baku yang dibawakan oleh seniman lamut di Kalimantan Selatan.

Kisah Kasan Mandi dan Siti Jungmasari

Tersebutlah kisah dua kerajaan yang bernama Kerajaan Palinggam dan Kerajaan Mesir. Raja dari kedua negara itu bersaudara, yang tua bernama Prabu Indera Bayu, yang muda Indera Kasmaran

Ratu Bungsu, Permaisuri Indera Bayu bermusyawarah dengan suaminya, Indera Bayu, Raja Pasak Palinggam yang mereka bicarakan adalah mencari jalan bagaimana caranya agar mereka bisa dikaruniai anak. Ratu Bungsu mengajak suaminya, Raja Indera Bayu mandi badudus di Sumur Tanjung Alimunan, di Pulau Madumanyan, bersama-sama Raja Mesir beserta Ratu Kasmaran. Kedua raja tersebut belum mempunyai seorang putra pun juga, meskipun usia perkawinan mereka sudah mencapai dua windu.

Raja Mesir beserta Ratu Kasmaran menerima ajakan saudaranya dan berangkatlah mereka ke Pulau Madumayan dengan diiringi oleh empat ratus lima puluh orang pengiring. Sebelum berangkat, kedua raja tersebut telah sepakat membuat perjanjian yang isinya apabila Raja Mesir mendapat anak perempuan maka harus ditembakkan meriam gantar alam, apabila Raja Pasak Palinggam memperoleh anak laki-laki, maka mariam Gantar Bumi harus pula ditembakkan. Mereka juga bernazar bila mendapatkan anak yang berlainan jenis akan menjodohkan keduanya. Setelah mereka mandi badudus di Pulau Madumayan, Raja Indera Bayu di karuniai seorang putra yang diberi nama Kasan Mandi Sadia Mandi dan Raja Indera Kasmaran dikaruniai seorang putri yang diberi nama Putri Jungmasari. Saat Kasan Mandi berusia tiga tahun, pemeliharaannya diserahkan kepada Lamut karena Lamut sebenarnya orang yang sakti dan bijaksana. Menjelang dewasa Lamut mengajak
Kasan Mandi berlayar untuk mencari pengalaman. Kapal yang mereka pergunakan untuk berlayar adalah kapal Naga Ulit Naga Umbang yang dibuat oleh paman Lamut sendiri. Kapal tersebut sangat istimewa dapat terbang dengan sendirinya sesuai dengan keinginan pemiliknya.

Kembali diceritakan Putri Jungmasari yang tinggal di dalam kamar delapan pintu, delapan lapis, tidak seorang pun dapat melihatnya. Mendengar akan kecantikan Jungmasari maka Sultan Aliuddin, Raja Pagar Ruyung ingin mengambilnya sebagai permaisuri. Raja ini adalah seorang Raksasa. Syamsuddin dan Amaruddin diutus ke negeri Mesir melamar putri Jungmasari. Mesir akan dihancurkan apabila lamaran ditolak. Lamaran terpaksa diterima dan kerajaan Mesir dikuasai Sultan Aliuddin.

Sementara itu, Kasan Mandi yang mendengar kecantikan Putri Jungmasari pun tertarik untuk memperistrinya. Dengan kesaktian Lamut, Kasan Mandi berubah menjadi burung Simbangan Laut dan terbang ke kediaman Putri Jungmasari. Simbangan Laut sebagai penjelmaan dari Kasan Mandi bertengger di jendela kamar Putri Jungmasari sambil berpantun

$$
\begin{gathered}
\text { jaruju padang jumampai } \\
\text { (jaruju padang jumampai) } \\
\text { Paikat laki dadayan kain } \\
\text { (rotan jemuran kain) } \\
\text { Kalau juduh baluman sampai } \\
\text { (apalah juduh belum sampai) } \\
\text { hakikat hati kada kalain } \\
\text { (hakekat hati hanyalah satu) }
\end{gathered}
$$

Simbangan laut berhasil memikat hati Jungmasari, terbukti dengan ditangkapnya burung tersebut dan langsung dimasukkannya ke dalam kelambu. Simbangan Laut terbang kembali ke kapal Naga Ulit Naga Umbang. dan kembali ke ujud semula dan memberitahukan keadaan kerajaan Mesir yang telah dikuasai kerajaan Pagar Ruyung dengan patih-patihnya Jamaluddin, julak Ludin, Syamsuddin. Naga Ulit Naga Umbang berlayar melewati Pagar Ruyung sebelum sampai di daerah tersebut kapal mereka macet, tidak 
dapat bergerak maju dan mundur. Labai Buranta dan Lamut menyelam ternyata kapal tersebut terhalang oleh rantai besi yang lebih besar dari kapal Naga Ulit Naga Umbang. Lamut orang yang sakti mengeluarkan ilmu kebatinannya. Dengan kesaktiannya rantai besi kembali menjadi air.

Sesampainya rombongan kapal Kasan Mandi di Kerajaan Mesir, Lamut kembali memperlihatkan kesaktiannya dengan mengubah Kasan Mandi menjadi kanak-kanak, ketika memasuki kerajaan Mesir. Tangisan kanak-kanak ini menimbulkan simpati siapa saja yang mendengarnya. Kabarnya tentang simpatiknya tangis kanak-kanak ini sampai ke telinga Putri Jungmasari. Putri pun berkenan untuk menjenguknya. Setelah melihat Putri Jungmasari, anak tersebut mengulurkan tangannya untuk digendong. Begitu pula Putri Jungmasari ketika memandang anak yang berada di dalam kapal Naga Ulit Naga Umbang ketika itu pula putri ingin memangkunya. Tangisan anak berhenti pada saat ia berada dalam pangkuan Putri Jungmasari dan langsung dibawa ke istana. Tiba di istana si anak kembali menjadi Kasan Mandi Sadia Mandi yang tampan perkasa. Terjadilah peperangan antara pihak Lamut dengan Raja Aliuddin dengan kemenangan berada di pihak Lamut. Akhirnya, Kasan Mandi menikah dengan Putri Jungmasari.

Pada saat Kasan Madi dan Putri Jungmasari dewasa, mereka menjadi sepasang suami istri yang hidup rukun dan bahagia.

\section{Revitalisasi Kesenian Lamut Melalui Kegiatan Bengkel Sastra}

Revitalisasi menurut KBBI (Tim Penuyusun 2008:1172) mengandung arti perbuatan menghidupkan atau menggiatkan kembali. Berdasarkan kondisi kesenian lamut saat ini upaya revitalisasi terhadap kesenian lamut sangat diperlukan. Oleh sebab itu, Balai Bahasa Provinsi Kalimantan Selatan bekerja sama dengan Badan Pembinaan dan Pengembangan Bahasa melakukan kegiatan revitalisasi terhadap kesenian lamut ini. Perwakilan pelajar setingkat SMU diundang dari seluruh kabupaten dan kota di
Provinsi Kalimantan Selatan untuk mengikuti pelatihan kesenian lamut di hotel Victoria Banjarmasin. Adapun yang membimbing pelajar tersebut tidak lain adalah seniman lamut sendiri, yaitu Gt Jamhar dan Gt Nafiah. Selain itu, revitalisasi kesenian lamut juga dilakukan oleh Balai Bahasa Provinsi Kalimantan Selatan melalui kegiatan bengkel sastra di Kabupaten Tanjung dan Marabahan.

Hasil dari pelatihan kesenian lamut ini cukup memuaskan. Banyak lahir bibit-bibit baru yang potensial yang dapat diharapkan menjadi seniman-seniman lamut berikutnya. Akan tetapi, sedikitnya ruang tampil bagi mereka yang telah mengikuti pelatihan di masyarakat menjadi permasalahan tersendiri. Oleh sebab itu, perhatian dan kepedulian dari instansi terkait seperti Dinas pendidikan, pemerintah provinsi, kota, dan kabupaten serta mutlak diperlukan demi menjaga kelestarian kesenian lamut ini.

Menurut Saefuddin (2006: 3) Kegiatan apresiasi sastra (Bengkel Sastra) adalah untuk meningkatkan apresiasi siswa terhadap karyakarya sastra, baik terhadap sastra yang diajarkan di sekolah maupun sastra di luar sekolah; seperti sastra daerah yang merupakan kekayaan budaya dari masyarakat Banjar itu sendiri. Dengan porsi yang sangat terbatas di sekolah, Balai Bahasa Provinsi Kalimantan Selatan turut berpartisipasi dalam melakukan kegiatan pembinaan dan pengembangan mengenai peningkatan apresiasi sastra dalam wadah bengkel sastra yang melibatkan siswa-siswa sekolah juga kalangan remaja pada umumnya. Kegiatan Bengkel Sastra di Kalimantan Selatan, baik oleh wadah sanggarsanggar kesastraan secara mandiri maupun melalui lembaga; seperti perguruan tinggi sudah dimulai sejak tahun 80-an. Sementara itu, Balai Bahasa Provinsi Kalimantan Selatan baru mulai secara berturut-turut sejak tahun 2000 hingga sekarang telah melaksanakan kegiatan bengkel sastra hampir di semua kota dan kabupaten di Kalimantan Selatan.

Kegiatan bengkel sastra pada tahun 2013 difokuskan untuk merevitalisasi kesenian lamut yang diduga mempunyai potensi untuk mengalami kepunahan. Oleh sebab itu, Balai 
Bahasa Provinsi Kalimantan Selatan mengadakan bengkel sastra salah satunya di Kabupaten Tabalong khusus untuk merevitalisasi kesenian lamut ini. Peserta bengkel adalah siswa-siswa tingkat SLTA yang ada di Kabupaten Tabalong dengan memberikan kesempatan bagi siswasiswa yang memiliki minat untuk mengikuti kegiatan Bengkel Sastra (gambar 4). Dengan dilaksanakannya kegiatan tersebut diharapkan peningkatan apresiasi sastra siswa-siswi di Kabupaten Tabalong lebih meningkat dan terwujud sebuah wadah-wadah baru yang menaungi insaninsan apresiator di bidang kesasatraan Indonesia dan daerah terkhusus lagi kesenian lamut.

Adapun tujuan kegiatan bengkel sastra khusus lamut ini adalah:

1) agar siswa mengenal, memahami, dan menghayati berbagai karya sastra, baik sastra modern atau sastra lama di Indonesia dan perkembangannya;

2) agar siswa mampu bersikap peka dan apresiatif terhadap karya sastra daerah di wilayah siswa tempat siswa tinggal untuk menggali potensi budaya lokal;

3) agar siswa dapat meningkatkan minat, bakat, dan kemampuannya dalam menulis dan memahami teater tradisional lamut;

4) agar siswa dapat meningkatkan minat, bakat, dan kemampuannya dalam mementaskan lamut di panggung terbuka; dan

5) agar kemampuan yang dimiliki siswa dapat terasah dengan baik setelah mengikuti pelatihan bengkel sastra (lamut).

Peserta Peningkatan Apresiasi Sastra melalui bengkel sastra ini adalah siswa SLTA Negeri/Swasta di Kabupaten Tabalong sebanyak 40 peserta. Pelaksanaan kegiatan bengkel sastra ini dibimbing oleh dua orang palamutan asal Kalimantan Selatan, yaitu Gt. Nafiah dan Bapak Masrun.

Materi sajian bengkel sastra ini menitikberatkan pada teater tradisional lamut, mencakup aspek teori dan praktik. Cakupan materi tersebut secara umum dapat diperinci sebagai berikut.
Teori berupa:

1) Pengantar Apresiasi Sastra;

2) Proses Penulisan Lamut;

3) Teknik Bermain Lamut;

Praktik berupa:

1) Teknik Bermain Lamut;

2) Pendalaman untuk Pementasan Lamut;

3) Pementasan Seni Teater Tradisonal Lamut.

Setelah menjalani pelatihan selama empat hari, baik teori maupun praktik, siswa-siswa yang menjadi peserta bengkel sastra pada akhir acara diminta untuk mementaskan kesenian lamut yang mereka pelajari (gambar 5). Hasilnya sungguh tidak mengecewakan para siswa-siswa tersebut mampu mementaskan kesenian lamut dengan baik. Mereka secara perseorangan maupun kelompok sanggup mementaskan kesenian lamut dengan baik. Hal itu cukup menggembirakan, mengingat di awal pelatihan banyak siswa yang tidak mengetahui tentang lamut dan cara mementaskannya. Pelatihan bengkel sastra khusus lamut ini ternyata terbukti efektif sebagai media revitalisasi bagi sebuah kesenian yang disinyalir akan mengalami kepunahan. Dengan demikian, mengangkat dan memberdayakan kembali kesenian lamut ke tengah-tengah masyarakat melalui Bengkel sastra telah menjadi sebuah keniscayaan.

Sumbangan program Balai Bahasa Provinsi Kalimantan Selatan melalui bengkel sastra telah menjadi sebuah media pembelajaran yang efektif bagi penumbuhkembangan kembali salah satu kesenian masyarakat Banjar, yaitu lamut ke tengah-tengah masyarakat. Akan tetapi, Pemberdayaan kembali peserta didik pasca pelatihan juga menjadi sebuah permasalahan yang tidak kalah penting. Kesenian lamut ini akan kembali tumbuh dan berkembang bila masyarakat pengusungnya juga memberi ruang untuk hal tersebut. Baik melalui perlombaan, festival, maupun dipentaskan langsung di tengah-tengah masyarakat, seperti mempertunjukkannya pada saat pesta perkawinan, lokakarya budaya, ulang tahun daerah, provinsi, dan lain sebagainya.

Kerja sama Balai Bahasa Provinsi Kalimantan Selatan dengan dinas atau instansi terkait seperti Dewan Kesenian Daerah, Dinas Kebudayaan, 
Taman Budaya, sekolah-sekolah di provinsi Kalimantan Selatan mutlak diperlukan untuk lebih menumbuhkembangkan kembali kesenian lamut ini. Harapan ke depan semoga kesenian lamut ini tetap hidup dan mewarnai kehidupan masyarakat Banjar sebagai pemilik dan pengusung kesenian lamut itu sendiri.

\section{PENUTUP}

Revitalisasi sastra kesenian lamut yang diadakan oleh Badan Pengembangan dan Pembinaan Bahasa Jakarta bekerja sama dengan Balai Bahasa Provinsi Kalimantan Selatan mendapatkan apresiasi yang sangat positif, baik dari sastrawan itu sendiri, para guru, para siswa dan pihak-pihak terkait. Hal itu disebabkan melalui kegiatan revitalisasi ini kesenian-kesenian daerah yang mulai terancam punah mendapatkan nafas baru untuk kembali memunculkan keberadaannya.

Keberadaan sebuah kesenian daerah seperti lamut sebenarnya harus dipertahankan dan dilestarikan. Hal itu disebabkan melalui kesenian daerah itu identitas sebuah daerah dan bangsa dapat diperkenalkan. Selain itu sebuah kesenian daerah seperti lamut sebenarnya telah ikut membantu pembentukan pola pikir, sikap, dan tingkah laku dari masyarakat pendukungnya. Hal itu disebabkan dalam setiap sastra daerah seperti lamut sebenarnya banyak memuat nilai-nilai tentang kearifan hidup yang dapat dijadikan acuan dalam kehidupan pribadi, masyarakat, bangsa, dan bernegara.

\section{DAFTAR PUSTAKA}

Asmuni, Fahrurazie. 2012. Sastra Lisan Banjar Hulu. Landasan Ulin: Penerbit Panakia

Effendi, Rustam. 1996. Sastra Daerah. Banjarmasin: FKIP Banjarmasin.

Jarkasi dan Djantera Kawi. 1996. Deskripsi Lamut, Teater Tutur Rakyat Kalimantan Selatan. Depdikbud: Bagian Proyek Pembinaan Kesenian Kalimantan Selatan.

Mugeni, Agus Yulianto, dan Saefuddin. 2004.

Sketsa Sastra Kalimantan Selatan: Lamut.

Banjarbaru: Balai bahasa Banjarmasin.

Saefuddin. 2006. Laporan Pelaksanaan Bengkel Sastra di Kabupaten Kotabanu. Banjarbaru:

Balai Bahasa Banjarmasin.

Sanderta, Bahtiar. 1988. Kesenian Lamut. Banjarmasin: Taman Budaya
Sudjiman, Panuti. 1995. Memahami Cerita Rekaan. Jakarta: Pustaka Jaya.

Seman, Syamsiar. 1981. Kesenian Lamut dan Madihin sebagai Media Tradisional yang Komunikatif. Banjarmasin: Depdikbud. 1988. Kesenian Rakyat Kalimantan Selatan "Lamut". Taman Budaya Provinsi Kalimantan Selatan.

Semi, M. Atar. 1990. Anatomi Sastra. Padang: Angkasa.

Tim Penyusun. 2008. Kamus Besar Bahasa Indonesia. Jakarta: Gramedia Pustaka Utama

Wellek, Rene dan Austin Werren.1995. Teori Kesusastraan. Terjemahan oleh Melanie Budianta. Jakarta: Gramedia. 